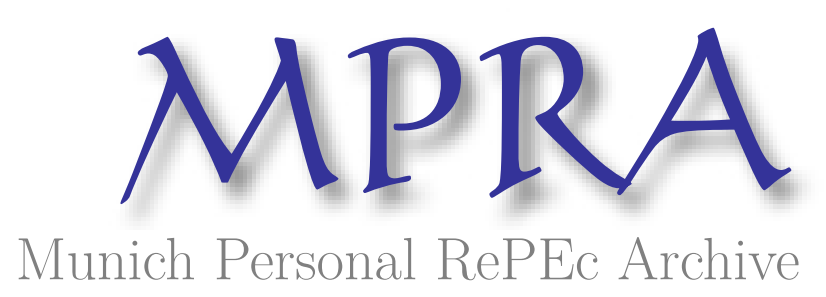

\title{
Inflationary Implication of Gold Price in Vietnam
}

Siregar, Reza Yamora and Nguyen, Thi Kim Cuc

ASEAN+3 Macroeconomic Research Office (AMRO)

12 April 2013

Online at https://mpra.ub.uni-muenchen.de/46157/

MPRA Paper No. 46157, posted 14 Apr 2013 09:57 UTC 


\title{
Inflationary Implication of Gold Price in Vietnam
}

\author{
$\underline{\text { Siregar, Reza Yamora and Nguyen, Thi Kim Cuc }}{ }^{a}$
}

April 2013

\begin{abstract}
:
The sustained elevated gold price domestically, hovering persistently above the global market price, underscores the peculiar nature of the gold market in Vietnam and the resiliently strong demand for gold in the local market. In particular, the movements in the price of gold seem to lead a symmetrical trend in the headline inflation since the outbreak of the 2007 global financial crisis. The primary objective of this study is therefore to assess possible inflationary consequence of the gold price movements in Vietnam. Past studies demonstrate that if gold could be viewed as a financial asset, shifts in the gold price should be monitored as one of the determining factors of inflation. Yet, hardly any study has assessed potential inflationary implication of gold in Vietnam, especially during the recent years of volatile and double-digit inflation rates.
\end{abstract}

Key Words: $\quad$ Gold Price; Vietnam; Money Demand; and Inflation

JEL Classification: C24; E31; E41 and E52

a/ Siregar, Reza Yamora (rezasiregar@yahoo.com) (correspondence author) and Nguyen, T.K.C. (thikimcuc.nguyen@amro-asia.org) are with the ASEAN+3 Macroeconomic Research Office (AMRO) in Singapore. Views expressed in this paper are of the authors only and do not necessarily represent those of the management of AMRO. The usual caveats apply. 


\section{Introduction}

Gold is more often analyzed as a commodity, but unlike other commodities it has the distinctive value of also being used as a store of wealth. A growing set of studies, such as Garner (1995), Mahdavi and Zhou (1997) and Tkacz (2007), have further argued that if gold is viewed as a financial asset, changes in the gold price or return should also be monitored as part of leading indicators or even one of the drivers of inflation. The role of gold price in anchoring inflation may have been less debated in recent years, but it was at the core of the policy deliberations during the Gold Standard period. The widespread dissatisfaction with high inflation in the late 1970s and early 1980s brought about a renewed interest in the gold standard (Bordo (2002)). With the rising and increasingly more volatile global gold price, particularly since 2005 , it is highly warranted that monetary policy makers pay close attention to the fluctuations of the gold price, in both local and global markets.

Among Asian emerging markets, the role of gold in the overall monetary sector and price stability picture is arguably most apparent in the case of Vietnam. While its industrial uses remain limited, confining mainly to jewellery fabrication and medical treatment, gold has been a traditional form of savings and a parallel currency for decades. As such, banks in Vietnam were allowed to borrow and lend gold since the early 2000s. The sustained elevated price of gold in the country, hovering persistently above its global market price, underscores the peculiar nature of the gold market in Vietnam and the resilient demand for gold in the local market (Figure 1). Furthermore, since the outbreak of the global financial crisis (GFC) in 2007, the movements in the price of gold seem to lead the fluctuation in the headline inflation (Figure 2).

The adverse effects of inflation are well known, and for Vietnam, price instability has been argued to be a primary factor in stifling economic development (Goujon (2006) and Nguyen, Cavoli and Wilson (2012)). ${ }^{1}$ Achieving price stability has therefore been one of the core objectives of the overall macroeconomic management policy in Vietnam. Tran (2009)

\footnotetext{
${ }^{1}$ Between 2001 and 2006, the year-on-year rise in the consumer price index was averaging around 5 per cent per month. Following the outbreak of the global financial crisis in 2007, the rate jumped to above 28 per cent in 2008 before moderating to around 7 to 9 per cent in the following two years. With another episode of escalating global economic uncertainty in 2011 , the annual headline inflation peaked in August 2011 at above 23 per cent.
} 
observes that the State Bank of Vietnam (SBV) appeared to adjust their monetary policies in response to the gap between the domestic and global gold prices in the post-1992 period, suggesting a possible perceived link between inflation and gold price movements in Vietnam.

The primary objective of this study is therefore to assess any potential inflationary consequence of the gold price in Vietnam. In particular, three pertinent policy questions will be addressed in this paper. First, has the fluctuation in the gold price been inflationary during the past decade? Second, has the pass-through of gold price shock to domestic price level become more significant throughout the turbulent economic and financial episodes, especially in the post 2007 GFC? Lastly, has the domestically driven component of gold price change been inflationary? To our knowledge, hardly any study has been done on these issues in Vietnam. While inflation in Vietnam has been the focus of many recent works, none of them have explicitly explored the role of gold in explaining the high inflation in the country, especially during the post-2007 period. By covering the period from January 2001 to December 2011, this paper fills this significant gap in the literature.

Another important contribution of this study is the adoption of the Markov-Switching Vector Autoregressive (MS-VAR) framework for empirical testing. As both inflation and gold price display significant volatilities during the observed period, the short-run dynamics between these two variables should arguably experience frequent changes as well. Furthermore, as the aim of our study is to compare and contrast the inflationary consequence of gold price during stable vis-à-vis turbulent periods, wherein the hidden states (stable or turbulent) may follow an exogenous process, the parameter constancy assumption of traditional linear testing, such as the Ordinary Least Square approach, proves to be too restrictive. We therefore employ the MS-VAR approach to allow for the nonlinearity and time-varying short-run dynamics in the relationships between inflation variable and its possible determinants. To our knowledge, this approach has hardly been considered in the past studies of inflation in Vietnam. 
The remainder of the paper is organized as follows. Next section presents a brief literature review on inflation in Vietnam and the inflationary implication of gold price. Section 3 discusses some stylized facts about inflation and the gold market in Vietnam. A theoretical framework of portfolio demand for money is applied in Section 4 to include gold price as one of the determining factors of inflation in Vietnam. Section 5 introduces the empirical testing approaches adopted in the paper. In this section, the application of the MS-VAR model and the empirical findings will be fully discussed. Finally, Section 6 ends the paper with policy implications and concluding remarks.

\section{Inflation and Gold Price: A Brief Literature Review}

\subsection{Inflation in Vietnam}

A proliferation of studies has focused on the inflation puzzle in Vietnam. Different working models have been adopted to examine the roles of the following possible rootcauses of inflation in the country, including: $(i)$ cost-push factors such as external price shocks and budget deficit increases; (ii) demand-pull factors such as money supply, total output, interest rates, and inflation expectations; and (iii) purchasing power parity (PPP)related factors such as exchange rates.

Covering the period of strategic economic reforms from a planning economy into a market-oriented one, also known as Doi Moi, Nguyen Tri Hung (1999) provides a narrative account of inflation in Vietnam between 1980 and 1995. As Vietnam remained a relatively closed economy during this entire timespan and the financial markets were severely underdeveloped, the author finds that raising deposit rates and imposing credit controls were effective in bringing down inflation from three-digit figures in the 1980s to much lower levels in the following decade. However, these instruments would prove to be less effective when the economy became more open, requiring a parallel process of removing supply rigidities and structural bottlenecks in the domestic market. 
Camen (2006) examines the determinants of inflation in Vietnam between 1996 and 2005 against the official stance that inflation in Vietnam is not a monetary phenomenon but instead a result of supply shocks. This study applies a Vector Autoregressive (VAR) model to explore the role of external factors (such as U.S. money supply, commodity prices) and domestic factors (such as monetary aggregates, credit, interest rates, and foreign exchange rate). Contrary to the official viewpoint, the study finds that credit to the economy was the most important variable in explaining CPI movements, especially at the 24-month horizon. Commodity prices and exchange rate, and U.S. money supply are also found important in explaining the headline inflation in Vietnam during the observed period.

Goujon (2006) investigates the determinants of inflation in the dollarized economy of Vietnam in the 1990s using a two-step cointegration procedure. The study highlights the impact of exchange rate variations on the broad money supply and the dollar-denominated price of some non-tradable goods in the context of dollarization, and on inflation accordingly.

Looking at a more recent decade, Nguyen and Nguyen (2010) study macroeconomic determinants of inflation in Vietnam between 2000 and 2010 by first applying a baseline model consisting explanatory variables such as industrial output, broad money, interest rate and exchange rate, and later expanding the model to include domestic credit, trading value of the stock exchange, import price index, world price of rice, and cumulative budget deficit. The authors find that inflation inertia played a significant role in explaining current inflation in Vietnam, followed by pass-through impacts of exchange rate and global inflation. In addition, money supply and interest rate had impacted, although with delay, short-run inflation. Meanwhile, the inflationary consequence of cumulative budget deficits was found insignificant.

Bhattacharya and Duma (2012) examine the mechanism of monetary policy transmissions in Vietnam between 1998 and 2010 by modelling inflation as a function of the money supply, real GDP, nominal effective exchange rate, foreign inflation, and real interest rate. The study finds that real interest rate has a significant negative impact on core inflation. 
Credit growth has little impact on inflation in the short- to medium-term given the low elasticity recorded at time horizons of eight quarters or less.

Nguyen, Cavoli, and Wilson (2012) explore the determinants of CPI inflation in Vietnam between 2001 and 2009 by building up on Goujon (2006)'s model and using a range of standard time series estimation techniques. Although the paper aims to examine the particular role of the exchange rate in explaining inflation, it finds that inflation inertia, money supply, and external cost shocks (increases in global oil and rice prices) were the most significant determinants of inflation in Vietnam from 2001 to 2009. As inflation inertia, or sticky inflation expectations, could be explained partly by the tendency to accept relatively high inflation rates to accommodate economic growth and the lingering memory of hyperinflation which lasted well into the 1990s, the authors posit that the pursuance of a largely fixed exchange regime would impose a monetary discipline on Vietnamese authorities on the one hand and help anchor inflation expectations on the other hand.

\subsection{Gold Price as a Leading Indicator for Inflation}

Whereas an ample number of studies have attempted to explain inflation in the dollarized context of Vietnam, surprisingly none have been carried out so far to understand the inflationary implication of gold prices in Vietnam given the high degree of 'goldization' in this economy. As Tran (2009) suggests, SBV appeared to follow closely movements in the domestic gold price and its gap with the global gold price during the post-1992 period. The likely link between inflation and gold price movements in Vietnam therefore warrants a more in-depth study.

Garner (1995) notes that an increase in the price of gold might precede an increase in the general inflation rate as the gold price would contain information about inflation expectations. Empirically, the price of gold lost its attraction as a leading indicator of inflation during the 1980s. Recent increases in the gold price and volatile inflation phenomenon have however led researchers to re-visit the indicator property of gold in predicting future inflation. The findings, nevertheless, have been far from reaching a consensus. Applying cointegration 
framework, Mahdavi and Zhou (1997) assess the effectiveness of gold and other commodities as leading indicators of inflation between 1958 and 1994, finding that the price of goods performed better than that of gold in predicting inflation. Comparing gold and inflation-linked bonds, Ranson (2005), meanwhile, postulates that gold price was an effective leading indicator of inflation, outperforming $\mathrm{CPI}$ and the price of oil in predicting future inflation.

Tkacz (2007) studies the indicator property of gold prices for inflation by modelling the inflation rate as a function of past return on gold at 6-, 12-, 18-, and 24-month horizons for 14 countries (OECD and non-OECD, inflation-targeting and non-inflation-targeting countries) on the monthly basis between 1994 and 2005. The empirical findings on 14 countries show that gold price led inflation in a number of countries up to 24-month horizon. The results are found the most significant for OECD countries that have adopted inflation targeting. Moreover, a comparison of gold price with other inflation estimators for the particular case of Canada demonstrates that gold remained statistically significant in explaining inflation when it was paired with other variables, such as money, output gap, U.S. inflation, or oil price.

\section{Inflation and Gold Price in Vietnam: Some Stylized Facts}

Gold has occupied a special place in the economy of Vietnam. The economic turmoil in the 1980s has led to hyperinflation and widespread distrust of the local currency. Vietnamese subsequently turned to gold, U.S. dollar and other hard currencies to store wealth and conduct major transactions. The series of economic reforms, or Doi Moi, enforced in the second half of the 1980s, helped restore the confidence in the Vietnamese dong to some extent but U.S. dollar usage and gold hoarding remain prevalent until today. To tap on gold savings, banks were allowed to mobilize gold and gold-guaranteed deposits from the populace upon provisions similar to those imposed on dong mobilization. Banks could also convert up to 30 per cent of their total gold and gold-guaranteed deposits into 
local currency funds and grant cash loans accordingly. ${ }^{2}$ Despite measures to mobilize gold into the formal banking system, gold hoarding continued to rise, especially after the 2007 GFC. Estimate of the gold amount kept outside the formal banking system rose to between 300 and 500 tonnes as of 2011 , close to about 20 per cent of Vietnam's nominal GDP. ${ }^{3}$

The 2000s marked the rapid rise in the domestic gold price and the return of high and volatile inflation in Vietnam (Figure 2). The domestic gold price experienced episodes of double-digit growths between 2002 and 2004, followed by a surge in the headline consumer price index (CPI) to nearly 10 per cent year-on-year in the late 2004 from insignificant levels prior to 2002. The gold price index - measuring the annual change in the domestic gold price level - became increasingly volatile with visible hikes between 2005 and 2007 whereas headline CPI moderated to around 7.5 per cent during the same period. The recent and arguably more noticeable co-movements between gold price index and headline CPI were observed from the onset of the 2007 GFC. After dipping by about 1 per cent in May 2007 from the level reported a year earlier, the gold price trended upwards to peak at a 40-per cent increase in August 2008. Headline CPI also rose to above 28 per cent in September 2008 - the highest level since the early 1990s. The gold price index continued to hike, spiking at above 60 per cent in 2009 and again in 2011. During this period, headline CPI soared rapidly to above 23 per cent in August 2011 before moderating subsequently.

To substantiate trend analyses, a simple but commonly applied Granger-Causality testing further insinuates that the movement of gold price granger-caused inflation in Vietnam during the observation period (Table 1$).{ }^{4}$ Concurrently, the test results also demonstrate that inflation does not granger-cause movement in the gold price. Furthermore, the causality relationship from gold price to inflation is significantly apparent during the post 2007 GFC period. Prior to presenting a more comprehensive empirical testing, next section will introduce a standard theoretical framework capturing the inflationary consequence of gold price movement.

\footnotetext{
${ }^{2}$ SBV's Decision 432/2000/QD-NHNN1 dated October 2000

${ }^{3}$ Phi D. M. (2011).

${ }^{4}$ Both of these series (inflation and change in the gold price) are found to be stationary, as demonstrated in Table 2.
} 


\section{A Monetarist Framework for Estimating Inflation in Vietnam}

Monetarists advocate that the rate of inflation $\left(\Delta p_{t}\right)$ should equal the growth rate of the nominal money supply $\left(\Delta m_{t}^{s}\right)$ minus the growth rate of real money demand $\left(\Delta m_{t}^{d}\right){ }^{5}$

$$
\Delta p_{t}=\left(\Delta m_{t}^{s}\right)-\left(\Delta \frac{m^{d}}{p}\right)_{t}
$$

All variables are in the logariarthmic forms. $(\Delta)$ denotes the first difference operation and $(t)$ captures time.

To estimate the real money demand, our approach is to use the portfolio balance model. Specifically, assuming that the asset choices of investors involve money and gold, the demand for real money balances can be written as follows:

$$
\left(\frac{m^{d}}{p}\right)_{t}=f\left(y_{t}, r_{t}^{m}, r_{t}^{g}\right)
$$

where: $(y)$ is the log of real income or real economic activity, $\left(r^{m}\right)$ is the own rate of return on money (to be proxy by deposit rate on local currency deposit rate in the banking system) and $\left(r^{g}\right)$ is the return from investment in gold.

Substituting Equation (2) into Equation (1) will yield the following general expression for domestic inflation:

$$
\Delta p_{t}=f\left(\Delta y_{t}, \Delta r_{t}^{m}, \Delta r_{t}^{g}, \Delta m_{t}^{s}\right)
$$

Equation 3a suggests that the level of domestic inflation is going to be influenced by the fluctuations in domestic income, expected rates of returns of money and gold investment, and domestic money supply. Expanding the relationships in Equation $3 a$ to include past explanatory variables at time $(t-j)$, where $(j \approx 1, \ldots)$, we can express the full relationship as:

$$
\Delta p_{t}=f\left(\Delta y_{t-j}, \Delta r_{t-j}^{m}, \Delta r_{t-j}^{g}, \Delta m_{t-j}^{s}\right)
$$

\footnotetext{
${ }^{5}$ Refer to McCallum (1989), Darrat and Arize (1990), Deme and Fayissa (1995), Rotheli (1990), and Siregar and Rajaguru (2005).
} 
The following first-order conditions should hold:

$$
\frac{\partial \Delta p_{t}}{\partial \Delta y_{t-j}}<0
$$

The rise in output/income or real economic activity should increase demand for money (Equation 2). Given money supply remains unchanged, the rise in the level of money demand relative to money supply will lead to a decline in the inflation rate (Equation 1). Hence, a rise in output will eventually cause inflation rate to decline.

$$
\frac{\partial \Delta p_{t}}{\partial \Delta r_{t-j}^{m}}<0
$$

A higher nominal interest rate on money should, ceteris paribus, lead to a higher demand for money (Equation 2). With the supply of money unchanged, the hike in money demand should cause a lower domestic inflation (Equation 1). Hence, a rise in the nominal interest rate could eventually lead to lower inflation.

$$
\frac{\partial \Delta p_{t}}{\partial \Delta r_{t-j}^{g}}>0
$$

The rise in the expected return of non-monetary asset such as gold should result in falling demand for money. In turn, given an unchanged supply of money, the fall in money demand should increase domestic inflation (Equation 1). This inflationary consequence of gold return hypothesis is going to be the primary subject of our empirical investigation.

$$
\frac{\partial \Delta p_{t}}{\partial \Delta m_{t-j}^{s}}>0
$$

Lastly, as clearly indicated by Equation 1, an increase in money supply, given everything else remains unchanged, should lead to a higher domestic inflation.

\section{Data and Empirical Testing}

\subsection{Data}

The price index $(p)$ is the consumer price index $(\mathrm{CPI})$. The monthly industrial production index is collected to proxy for the real economic activity $\left(y_{t}\right)$. The preferred 
measure of nominal interest rate on money $\left(r^{m}\right)$ is three-month deposit rate. The monetary aggregate (M2) is adopted for the money supply $\left(\mathrm{m}^{s}\right)$ variable. This monetary aggregate, measured in local currency, consists of the local currency (dong) in circulation outside banks along with dong-denominated and dollar-denominated bank deposits.

For the proxy of the return in gold investment $\left(r^{g}\right)$, the gold price, measured in local currency per Troy ounce, is selected. According to the General Statistics Office (GSO) of Vietnam, gold is not included in the CPI basket of the country. As will be elaborated further in the paper, three series of gold prices are employed in the testing. First is the global gold price. We generate a monthly dataset of global gold prices by taking the simple average of global daily gold prices quoted in Vietnamese dong by Bloomberg for each month. Second is the domestic gold price in Vietnam. GSO provides monthly annual change of the domestic gold price in local currency since January 2003. The Bloomberg database, on the other hand, provides domestic daily gold price in Vietnam from April 2007 to December 2011. To ensure the consistency between these two sets of data, we first convert the daily Bloomberg data into a monthly dataset and subsequently generate monthly annual changes for the period from April 2008 to December 2011. We find the growth series to be consistent with the data reported by GSO. Using the monthly annualized growth rates reported by GSO, we extend the Bloomberg domestic gold price in Vietnam quoted in dong backward to January 2003. Finally, we derive the gold price gap to capture the domestic component of the gold price by subtracting the monthly global gold price from the domestic gold price.

To ensure consistency, the monthly data for each variable is predominantly sourced from the GSO, with the exception of the gold price and interest rates. All variables are in the log-form and seasonalized to remove the transient noises. The month-to-month percentage changes of the variables are then calculated to arrive to $\left(\Delta p_{t}, \Delta y_{t}, \Delta r_{t}^{m}, \Delta r_{t}^{g}, \Delta m_{t}^{s}\right)$. The observed period spans from January 2001 to December 2011, unless otherwise noted.

\subsection{Empirical Testing}

\subsubsection{Unit-Root Property Testing}


As briefly indicated in the introduction, the MS-VAR approach will be employed to estimate Equation 3b. Prior to conducting the MS-VAR testing, the unit-root properties of each variable will be first examined. Given the potential presence of structural breaks in time-series variables, the low-power of ADF test may not be sensitive enough to differentiate a stationary series from a non-stationary one. To evaluate the unit-root property more structurally, we apply another unit-root test introduced by Banerjee, Lumsdaine and Stock (BLS (1992)). Their work investigates further the possibility that aggregate economic time series can be characterized as being stationary around 'a single or multiple structural breaks'. BLS extends the Dickey-Fuller t test by constructing the time-series of rollingly computed estimators and their t-test statistics.

For the BLS Unit-Root test, we report the unit-root test at the 95-per cent confidence level. Both the minimal and maximal Dickey-Fuller t-test statistics of the BLS rolling test are found to be significantly larger than each critical value, respectively (Table 2). These test results confirm the findings of the ADF tests that the null hypothesis of nonstationarity at the 5-per cent critical value cannot be rejected at the level for all the key variables. ${ }^{6}$ In short, the first differences of the series for all relevant variables, as presented in Equation $3 b$, are stationary.

\subsubsection{Markov-Switching Vector Autoregressive (MS-VAR) Frameworks}

To answer the set of questions listed in the Introduction section of this paper, we will employ the MS-VAR testing. There are at least several primary advantages of this testing over the other standard approaches such as the OLS estimation. To start, the MS-VAR approach allows for the non-linearity and time-varying short-run dynamics. If we observe the inflation rates of Vietnam (Figure 2), the series demonstrates episodes of sharp expansions and contractions. Therefore, it would not be reasonable to expect a linear model to capture these frequent changing behaviours. Second, the Markovian property recognizes and regulates the possibilities that the structural switch may prevail for a random period of time.

\footnotetext{
${ }^{6}$ For the sake of brevity, the ADF test results are not reported but can be made available upon request.
} 
Hence, the MS-VAR approach allows us to test a more complex dynamic pattern, which includes periods of economic and financial crisis, without the need to break the sample periods into predetermined crisis and non-crisis periods, or to introduce a crisis dummy variable. In short, the MS-VAR is highly appropriate for the set of empirical objectives of this study. The dynamics of inflation in Vietnam may change from the period of stability to that of volatility in a random manner. Accordingly, it is only natural that the roles of explanatory variables listed in Equation 3b may have changed structurally during those two different states of economic conditions.

The MS-VAR framework adopted in this study is essentially extending Hamilton's (1989) Markov-Switching regime framework to the Vector Autoregressive (VAR) systems (see Krolzig, 1997; Sims, 1999; Valente, 2003). Our study considers three types of MS-VAR models that allows for either regime shifts in intercept term, variance-covariance matrix or autoregressive terms. Firstly, we will consider an M-regime $p$-th order MS-VAR model that allows for regime shifts in variance-covariance matrix. This model, the Markov-SwitchingHeteroscedastic-VAR or MSH(M)-VAR(p), may be written as follows:

$$
\mathbf{y}_{t}=\mathbf{v}+\sum_{i=1}^{p} \mathbf{A}_{i} \mathbf{y}_{t-i}+\boldsymbol{\varepsilon}_{t}
$$

Where $y_{t}$ is a K-dimensional observed time-series vector, $y_{t}=\left[y_{1 t}, y_{2 t}, \ldots ., y_{K t}\right]^{\prime}$ and for this paper matrix $y_{t}$ contains all variables used in Equation 3b. $v$ is a K-dimensional column vector of intercept terms, $v=\left[v_{1}, v_{2}, \ldots ., v_{K}\right]^{\prime}$; the $A_{i}$ are $(K \times K)$ matrices of autoregressive parameters; $\varepsilon_{t}=\left[\varepsilon_{1 t}, \varepsilon_{2 t}, \ldots, \varepsilon_{K t}\right]^{\prime}$ is a K-dimensional vector of Gaussian white noise process with a regime-dependent variance-covariance matrix. Note: $\varepsilon_{t} \sim \operatorname{NID}\left(0, \sum\left(s_{t}\right)\right)$. The regime-generating process is assumed to be a hidden Markov chain with a finite number of regimes/states $s_{t} \in\{1, \ldots ., M\}$ governed by the transition 
probabilities $p_{i j}=\operatorname{Pr}\left(s_{t+1}=j \mid s_{t}=i\right)$, and $\sum_{j=1}^{M} p_{i j}=1$ for $\forall i, j \in\{1, \ldots, M\}$. We can then collect all the conditional transition probabilities $p_{i j}$ into a transition matrix $(P)$ as follows:

$$
\mathbf{P}=\left[\begin{array}{cccc}
p_{11} & p_{12} & \cdots & p_{1 M} \\
p_{21} & p_{22} & \cdots & p_{2 M} \\
\vdots & \vdots & \ddots & \vdots \\
p_{M 1} & p_{M 2} & \cdots & p_{M M}
\end{array}\right]
$$

Secondly, we will consider an M-regime p-th order MS-VAR model that allows for regime shifts in both intercept terms and variance-covariance matrix. This model, the Markov-Switching-Intercept-Heteroscedastic-VAR or $\mathrm{MSIH}(\mathrm{M})-\mathrm{VAR}(\mathrm{p})$, may be written as follow:

$$
\mathbf{y}_{t}=\mathbf{v}\left(s_{t}\right)+\sum_{i=1}^{p} \mathbf{A}_{i} \mathbf{y}_{t-i}+\varepsilon_{t}
$$

Where $v\left(s_{t}\right)$ is a K-dimensional column vector of regime-dependent intercept terms, $v\left(s_{t}\right)=\left[v_{1}\left(s_{t}\right), v_{2}\left(s_{t}\right), \ldots ., v_{K}\left(s_{t}\right)\right]^{\prime} ; \varepsilon_{t} \sim N I D\left(0, \sum\left(s_{t}\right)\right)$ as in equation (4), and $s_{t} \in\{1, \ldots . ., M\}$.

Finally, we will consider a M-regime p-th order Markov-switching VAR that allows for state/regime shifts in all intercept terms, autoregressive parameters and variance-covariance matrix. This model, the Markov-Switching-Intercept-Autoregressive Heteroscedastic-VAR or $\operatorname{MSIAH}(\mathrm{M})-\operatorname{VAR}(\mathrm{p})$, may be written as follows:

$$
\mathbf{y}_{t}=\mathbf{v}\left(s_{t}\right)+\sum_{i=1}^{p} \mathbf{A}_{i}\left(s_{t}\right) \mathbf{y}_{t-i}+\varepsilon_{t}
$$

Where $v\left(s_{t}\right)$ is a K-dimensional column vector of regime-dependent intercept terms, $v\left(s_{t}\right)=\left[v_{1}\left(s_{t}\right), v_{2}\left(s_{t}\right), \ldots, v_{K}\left(s_{t}\right)\right]^{\prime} ;$ the $A_{i}\left(s_{t}\right)$ 's are $(K \times K)$ matrices of regime-dependent autoregressive parameters; $\varepsilon_{t} \sim N I D\left(0, \sum\left(s_{t}\right)\right)$ and $s_{t} \in\{1, \ldots ., M\} .^{7}$ It is important to note here that the different MS-VAR models discussed earlier are suitable for stationary series.

\footnotetext{
${ }^{7}$ All of the above Markov-switching VAR models will be estimated using the expectation-maximization (EM) algorithm (see Hamilton (1989) and Krolzig (1997)).
} 
As reported in Table 2, all the first-differenced variables listed in Equation 3 or $3 \mathrm{~b}$ are stationary series.

Based on the commonly used Akaike and Schwarz Criteria statistics, two period lags for the explanatory variables are considered. ${ }^{8}$ Furthermore, the likelihood linearity test and the Chi-square confirm that the MSIAH $(2,2)$ model is the most suitable to capture the relationship among the variables listed in Equation $3 b$ (Tables 3 and 4 ). ${ }^{9}$ In addition, we apply Davies (1987) bound test for the number of regimes. The test result rejects one state/regime specification in favour of the two-state model.

Has gold price/return been inflationary during the past decade? Has the inflationary consequence of gold been more apparent during the turbulent economic and financial periods? A number of key findings are worth highlighting from the MS-VAR test results posted in Tables 3-5.

As indicated by the relative sizes of the standard errors, State 1 or Regime 1 with a lower standard error of around (0.0019) captures the stable and falling inflation period, and Regime 2 is the volatile and rising inflation period with the standard error of $(0.0029)$. Furthermore, $\left(p_{11}\right)$ denotes the transition probability of Regime 1 (or stable regime) at time ( $t$ ) given that it was at Regime 1 at $(t-1)$, and it is equal to $(0.8628) .{ }^{10}$ On the other hand, $\left(p_{22}\right)$, the transition probability of State 2/Regime 2 (or volatile regime) at time $(t)$ given that it was at Regime 2 at $(t-1)$, is reported to be (0.8409). Based on the transition probabilities, the expected duration is approximately $\left(\frac{1}{\left(1-p_{11}\right)}\right) \approx 7.3$ months for Regime 1 of falling and stable inflationary period, and it is estimated to be longer than $\left(\frac{1}{\left(1-p_{22}\right)}\right) \approx 6.3$ months for Regime 2 of rising and volatile inflationary period.

\footnotetext{
${ }^{8}$ We also experimented with four lags. The results however were best reported at two lags.

${ }^{9}$ Please refer to Hamilton (1996) for a more in-depth discussion on these property tests.

${ }^{10}$ The sum of $\left(p_{11}\right)$ and $\left(p_{12}\right)$ equals to 1 . This satisfies one condition for the Markov-chain process to be ergodic (i.e. the states are recurrent, aperiodic and irreducible).
} 
As reported in Table 5, 71 months from January 2001 to December 2011 observations are reported during Regime 1, and 59 months of Regime 2. Based on the number of months fallen under Regime 2, the post-2007 period can conclusively be concluded as the volatile one. Around 39 out of 59 months, or about 66 per cent of the volatile Regime 2 are those months between January 2007 and December 2011. In contrast, less than 29 per cent of monthly inflations for the post-2007 period are under Regime 1.

Based on the significance of their coefficient estimates, the classic determinant factors of inflation, i.e. interest rate, money supply and income, are all found to be significant sources of inflationary pressures in Regime 1. Moreover, the signs of the coefficients are theoretically consistent. However the sums of coefficient estimates suggest that the impacts of money supply and income are relatively weak. The total coefficient estimates for the first and second lags for monthly changes in the money supply and income factors are reported to be close to zero (Table 3). The coefficient estimate for the interest rate factor, on the other hand, is significant, suggesting a rise in the nominal deposit interest rate by 1 per cent should lead to a fall in the inflation rate by $(0.026)$ per cent. ${ }^{11}$ Confirming the findings of early studies, inflation inertia has indeed been a major source of inflationary pressure in State 1 , with elasticity of around (0.60). Among the explanatory variables, movements in the gold price do not seem to have any impact on the inflation during this stable regime, as indicated by the insignificancy of its coefficient estimate.

Due to the overall softening economic growth, the income factor does not seem to influence price movements in Regime 2 (Table 4). In contrast, the coefficient estimate for the gold price movement at (t-2) is positive and significant during this volatile period. This finding suggests that the increasingly volatile gold price movements, especially since 2006, have become inflationary at a two-month lag. The rest of the primary drivers (inflation inertia, deposit rate and money supply) are found to be significant during Regime 2. Moreover, each of these root-causes of inflation contributed more significantly during the volatile regime, as

\footnotetext{
${ }^{11}$ The coefficient estimate of deposit interest rate at $(t-1)$ is $(-0.023)$ and at $(t-2)$ is $(-0.003)$. The sum of the coefficient estimates is therefore around $(-0.0026)$.
} 
can be depicted by the relatively larger coefficient estimates for each variable in Regime 2 than in Regime 1. Aside from inflation inertia, strong and volatile gold price and expansionary money supply, in particular, had sustained inflationary pressures, especially between 2008 and $2010 .^{12}$ The significant inflationary implication of money supply expansion has also been highlighted by previous studies such as Goujon (2006) and Nguyen, Cavoli and Wilson (2012). The overall finding underscores the fact that managing price stability in Vietnam has indeed become more challenging during the height and post-2007 global financial and the Eurozone sovereign debt crisis period.

Has the domestic component of gold price been inflationary? Based on the examination of SBV's Taylor-type reaction function, Tran (2009) claims that the domestic component of gold price, estimated as the difference between the domestic and global gold prices, do influence the SBV in adjusting their monetary policies. The study however does not empirically test the relationship between the gold price gap and inflation. More importantly, the study covers the timespan up to December 2002 only, leaving out the rapid rise in the gold price in the second half of the 2000 s.

To better answer this highly policy-relevant question, we run another round of MSVAR test on a slightly modified Equation $3 b$ by replacing the domestic gold price growth $\left(\Delta r^{g}\right)$ with the gold price gap $\left(\Delta r^{d g}\right)$, measured as the difference between log of domestic gold price in local currency and log of world gold price in local currency (Figure 1). ${ }^{13}$ Due to the availability of the data for the gold price gap, the sample observation covers the period from January 2003 to December 2011, as depicted in Figure 1. In general, the findings reported in Tables 6 and 7 are consistent with those reported in Tables 3 and 4, respectively. These additional test results reaffirm the significant contributions of the different drivers of the domestic inflation in Vietnam in both Regime 1 and 2. More importantly, the domestic

\footnotetext{
${ }^{12}$ After a brief period of moderation in 2002, money supply started expanding from 2003 onwards. Broad money grew by an average rate of 30 percent between 2003 and 2006 and rose to above 40 percent in 2007. As inflation declined from 23 percent in 2008 to 7 per cent in 2009 amidst softened economic growth, another round of aggressive money supply expansion was conducted in the early of 2009 and lasted until the end of 2010 . Broad money grew by 26 per cent in 2009, another 30 percent in 2010, before moderated to slightly above 15 percent at the end of 2011.

${ }^{13}$ Due to the availability of data series for the gold price gap, the sample observation covers the period from January 2003 to July 2012, as depicted in Figure 1.
} 
component of gold price has been found to play a significant role in pushing up price level during the period of price instability (Regime 2). However, it has no contribution to the price movements during the months of falling or stable inflation (Regime 1). This finding reaffirms the inflationary consequence of gold price movements, particularly during the post-2007 GFC period.

\section{Gold Price and Inflation: Policy Implications and Concluding Remarks}

As ensuring price stability has always been one key objective of Vietnam's macroeconomic policies ${ }^{14}$, this study tries to disentangle the inflation puzzle by examining a number of factors that may have contributed to the inflation rate between January 2001 and December 2011. Extending earlier works on inflation in Vietnam, we apply the monetarist theoretical framework and the two-state Markov-switching approach to assess the inflationary consequences of various factors during stable and volatile periods. More importantly, our work pays special attention at the inflationary consequence of the gold price movements in Vietnam which, to our knowledge, has never been empirically examined. Our study demonstrates the significant pass-through impact of the gold price and, notably, its domestic component on the headline CPI during the observed period. The findings hence warrant the need to develop an effective policy to manage the gold market in line with the overall price management effort in Vietnam.

In actuality, the State Bank of Vietnam had employed measures to mitigate the gap between the domestic and global gold prices since the early 1990s. A Gold Price Stabilization Fund was set up in 1995 in order to allow SBV to intervene in the gold market in case the domestic price deviated from the global price by a margin of three per cent. ${ }^{15} \mathrm{~A}$ number of conscious efforts were also made to streamline the regulatory framework. Decree 63 in 1993 officially recognized the private ownership of gold and allowed the private sector to participate in gold trading business which had been previously reserved for State-Owned-

\footnotetext{
${ }^{14}$ For example, see Government's Resolution 11/2011/NQ-CP dated 24 February 2011 on measures to curb inflation and to ensure macroeconomic stability and social security.

${ }^{15}$ SBV Decision 216/QD-NH7 dated 7 August 1995.
} 
Enterprises only. The production and external trade of gold bars, however, remained under the State control. ${ }^{16}$

Measures to further liberalize the gold market were implemented in the first half of the 2000s. Decree 174 in 1999 decentralized the production and trade of gold bars into qualified trading enterprises. Decree 64 in 2003 subsequently removed the minimum statutory capital requirements for gold production and trading enterprises. As a result, eight enterprises were given production licenses for gold bars whereas the network of gold trading enterprises widened to about 12,000 during this period. In terms of external trade, Vietnam remained to be a net gold importer until 2008. ${ }^{17}$ In addition to physical gold trading, a number of credit institutions and gold trading enterprises were allowed to conduct trading via loco gold accounts, an important step to connect the domestic gold market with global markets. ${ }^{18}$ A number of local gold trading floors were spontaneously formed without any legal framework in place to regulate their activities. The 'illegal' operation of these local gold trading floors and their linkages with the global market, however, allegedly resulted in detrimental losses to the involving parties between 2006 and 2009. 'Illegal' local trading floors were prohibited afterwards. SBV also requested credit institutions and gold trading enterprises to close their loco gold accounts by early $2010 .^{19}$

While the domestic price of gold moved largely in tandem with the global price in the early 2000s, volatilities returned in the second half of 2000s, especially in the post-2007 GFC period (Figure 1). The domestic-global price gap widened significantly to USD 100 to 150 per Troy ounce from the late of 2010 , except for a brief period in the second quarter of 2011. Gold export soared rapidly from 2009 whereas import was strongly discouraged, de facto turning Vietnam into a net gold exporter (Figure 3). ${ }^{20}$ Subsequent measures have been

\footnotetext{
${ }^{16}$ SBV either imported gold directly or authorized its subsidiary company (Vietnam Jewellery Corporation) with import licenses to do so during this period.

${ }^{17}$ Vietnam Economic Times (2007) estimated about 70 tonnes of gold were imported each year, corresponding to about USD

2.1 billion. Available export data point to an average value of USD 300 million of gold was exported annually between 2006 and 2008.

${ }^{18}$ SBV Circular 03/2006/TT-NHNN dated 2006

${ }^{19}$ SBV Circular 01/2010/TT-NHNN dated January 2010.

${ }^{20}$ Gold export between 2009 and 2011 is estimated to be about USD 8 billion. Gold import, however, was largely discouraged as a means to cut down the widened trade deficit. SBV only granted gold import licenses to a number of banks and gold trading companies, particularly in the second half of 2011 , to fill in the supply gap and to ease the domestic-global price gap. Gold
} 
implemented to narrow down the price gap, including the reversal of some earlier liberalization efforts. Most notably, SBV tightened its control over the gold market by, once again, monopolizing the production and external trade of gold bars from early $2012 .{ }^{21}$ An auction system was established in 2013 to allow SBV, as the sole importer and final supplier in the market, to allocate gold bars to qualified market participants. ${ }^{22}$ The domestic-global price gap, in the meantime, continued to widen and peaked at above USD 200 per Troy ounce in early 2013 (Figure 4).

In summary, our study underscores the complexity in price management for such a small, open economy with an increased appetite for gold investment as Vietnam, especially during volatile periods when the pass-through effect of the gold price onto inflation tends to become significant. The Government of Vietnam has apparently adjusted their policies in response to the gap between the domestic and global gold prices. Against this backdrop, the lack of a coherent, long-term vision toward the gold market has led to a series of ad-hoc, temporary measures to counter adverse developments, particularly in the second half of the 2000s. The domestic-global price gap, however, continued to enlarge as the domestic gold market remained disconnected with the global market. In this regard, China could provide an advanced example in early acknowledging the need to develop the domestic gold market as an integral part of the overall financial market and in close connection with the global market. ${ }^{23}$ In achieving such goal, necessary infrastructural conditions should be fully developed and the State's regulatory capability should be vigorously enhanced. These two important factors are, however, still missing in Vietnam.

\footnotetext{
import therefore stood at USD 4 billion between 2009 and 2011 . Vietnam, as a result, turned into a net gold exporter with a net export value amounting to USD 4 billion in the same period.

${ }_{21}^{21}$ Government's Decree 24/2012/ND-CP dated April 2012.

22 Prime Minister's Decision 16/2013/QD-Ttg dated 4 March 2013 and SBV's Circular 06/2013/TT-NHNN dated 12 March 2013.

${ }^{23}$ For more information about the domestic gold market in China, see World Gold Council (2010) and Shanghai Gold Exchange and People's Bank of China (2011).
} 


\section{References}

Bhattacharya, R. and Duma N. (2012), "Inflation Dynamics and Monetary Policy in Vietnam", IMF study presentation.

Bordo, M,D. (2002), "Gold Standard", Concise Encyclopaedia of Economics.

Camen, U. (2006), "Monetary policy in Vietnam: the case of a transition country", Bank for International Settlements (BIS) working paper series.

Darrat, A. F., \& Arize, A. C. (1990). "Domestic and international sources of inflation in developing countries: some evidences from the monetary approach", International Economic Journal, 4(4), pp. 55-69.

Davies, R.B. (1987), "Hypothesis Testing when Nuisance Parameter is Present Only Under Alternative", Biometrika, 74, pp. 33-43.

Deme, M. and Fayissa, B (1995), "Inflation, Money, Interest Rate, Exchange Rate, and Causality: The Case of Egypt, Morocco, and Tunisia", Applied Economics, Vol.27, pp.1219-1224.

Garner, C. A., (1995), "How Useful are Leading Indicators of Inflation?" Federal Reserve Bank of Kansas City Economic Review, Second Quarter, pp. 5-18.

Goujon, M. (2006), "Fighting Inflation in a Dollarized Economy: The Case of Vietnam", Journal of Comparative Economics, 34, no. 3, pp. 564-581.

Gray, S.F. (1996), "Modelling the Conditional Distribution of Interest Rate as a Regime Switching Process", Journal of Financial Economics, 42, pp. 27-62.

Hamilton, J.D. (1989), "A New Approach to the Economic Analysis of Nonstationary Time Series and the Business Cycle", Econometrica, 57(2), pp. 357-384.

Hamilton, J. and Susmel, R. (1994), "Autoregressive conditional heteroscedasticity and changes in Regime", Journal of Econometrics, vol. 64, pp. 307-333.

Hamilton, J.D. (1996), "Specification Testing in Markov-Switching Time Series Models", Journal of Econometrics, 70, pp. 127-157.

Krolzig, H-M (1997), Markov-switching vector autoregressions: Modelling, statistical inference, and application to business cycle analysis, Springer (Berlin and New York).

Mahdavi, S. and Zhou, S. (1997), "Gold and Commodity Prices as Leading Indicators of Inflation: Tests of Long-Run Relationship and Predictive Performance." Journal of Economics and Business, 49, 475-489.

McCallum, B.T. (1989), "Monetary Economics: Theory and Policy", MacMillan Publishing Co, NY.

Nguyen, T.H. (1999), "The Inflation of Vietnam in Transition", CAS discussion paper no. 22. 
Nguyen, T.T.H. and Nguyen, D. T. (2010)," Macroeconomic Determinants of Vietnam's Inflation in 2000-2010: Evidence and Analysis", Vietnam Centre for Economic and Policy Research working paper.

Nguyen, H.M., Cavoli, T. and Wilson, J.K. (2012), "The Determinants of Inflation in Vietnam, 2001-09", ASEAN Economic Bulletin, vol. 29, no.1, pp. 1-14.

Phi, D. M. (2011), "Bien phap nao de Nha nuoc su dung duoc so vang du tru trong dan" (Measures to Mobilize the Gold Amount kept in the Population), SBV Research and Exchange, available at SBV's website at www.sbv.gov.vn.

Ranson, D. (2005), “Inflation Protection: Why Gold Works Better than “Linkers"', H.C. Wainwright \& Co. working paper.

Rotheli, T.F. (1990), "Money Supply and Money Demand Determinants of Swiss Inflation", Swiss Journal of Economics and Statistics, vol. 126, Issue 1, pg.1-15.

Siregar, R. and Rajaguru, G. (2005), "Sources of Variations between the Inflation Rates of Korea, Thailand and Indonesia during the post-1997 crisis", Journal of Policy Modelling, 27, pp. 867-884.

Tkacz, G. (2004), "Inflation Changes, Yield Spreads and Threshold Effects." International Review of Economics and Finance, 13, pp. 187-199.

Tkacz, G (2007), "Gold Price and Inflation”, Bank of Canada Working Paper no.35, Ontario, Canada.

Vietnam Economic Times, "Tai kien nghi duoc xuat khau vang” (Repeated Call for Gold Export Quota), 19 July 2007.

Vuong Quan Hoang (2004), “Analysis on Gold and US Dollar in Vietnam's Transitional Economy”, Working Paper Centre Emile Bernheim WP-CEB no. 04-033, July 2004.

World Gold Council (2010), China Gold Report: Gold in the Year of the Tiger.

Shanghai Gold Exchange and People's Bank of China (2011), China Gold Market Report 2010. 
Table 1: Granger-Causality Test

Full Period: January 2001 - December 2011

\begin{tabular}{|l|c|c|c|}
\hline Null Hypothesis: \# of Lags = 2* & \# of obs & F-Statistics & Prob \\
\hline $\begin{array}{l}\text { Inflation does not Granger Cause Change in } \\
\text { Gold Price }\end{array}$ & 132 & 1.55685 & 0.2148 \\
\hline $\begin{array}{l}\text { Change in Gold Price does not Granger Cause } \\
\text { Inflation }\end{array}$ & & 5.08975 & 0.0075 \\
\hline
\end{tabular}

Pre-2007 Global Financial Crisis Period: January 2001 - December 2006

\begin{tabular}{|l|c|c|c|}
\hline Null Hypothesis: \# of lags = $\mathbf{1}^{\boldsymbol{*}}$ & \# of obs & F-Statistics & Prob \\
\hline $\begin{array}{l}\text { Inflation does not Granger Cause Change in } \\
\text { Gold Price }\end{array}$ & 72 & 0.07942 & 0.7789 \\
\hline $\begin{array}{l}\text { Change in Gold Price does not Granger Cause } \\
\text { Inflation }\end{array}$ & & 0.47103 & 0.4948 \\
\hline
\end{tabular}

Post-2007 Global Financial Crisis Period: January 2007-December 2011

\begin{tabular}{|l|c|c|c|}
\hline Null Hypothesis: \# of lags = 2* & \# of obs & F-Statistics & Prob \\
\hline $\begin{array}{l}\text { Inflation does not Granger Cause Change in } \\
\text { Gold Price }\end{array}$ & 60 & 1.79910 & 0.1750 \\
\hline $\begin{array}{l}\text { Change in Gold Price does not Granger Cause } \\
\text { Inflation }\end{array}$ & & 3.73455 & 0.0301 \\
\hline
\end{tabular}

Source: Authors' own calculation. */ the number of lags is based on the Akaike AIC statistics. 
Table 2: The BLS Rolling Unit-Root Test

\begin{tabular}{|c|c|c|}
\hline Variable & $\hat{t}_{D F}^{\operatorname{Max}}$ & $\hat{t}_{D F}^{M i n}$ \\
\hline$p_{t}$ & 0.901 & 0.335 \\
\hline$\Delta p_{t}$ & -2.259 & -5.354 \\
\hline$y_{t}$ & -0.886 & -1.824 \\
\hline$\Delta y_{t}$ & -8.785 & -11.991 \\
\hline$r_{t}^{m}$ & -1.276 & -3.102 \\
\hline$\Delta r_{t}^{m}$ & -4.994 & -9.658 \\
\hline$r_{t}^{g}$ & 1.783 & 0.154 \\
\hline$\Delta r_{t}^{g}$ & -7.768 & -8.030 \\
\hline$m_{t}^{s}$ & 1.654 & 0.609 \\
\hline$\Delta m_{t}^{s}$ & -1.703 & -6.091 \\
\hline \multicolumn{3}{|c|}{$\begin{array}{c}\text { Note: Critical values at } 5 \text { per cent level with the number of observation of around } 100 \text { are: } \\
- \text { The maximal DF statistics is }(-1.49) \text {; and } \\
\text { - The minimal DF statistics is }(-5.01)\end{array}$} \\
\hline
\end{tabular}


Table 3: Markov-Switching Test Results for Regime 1

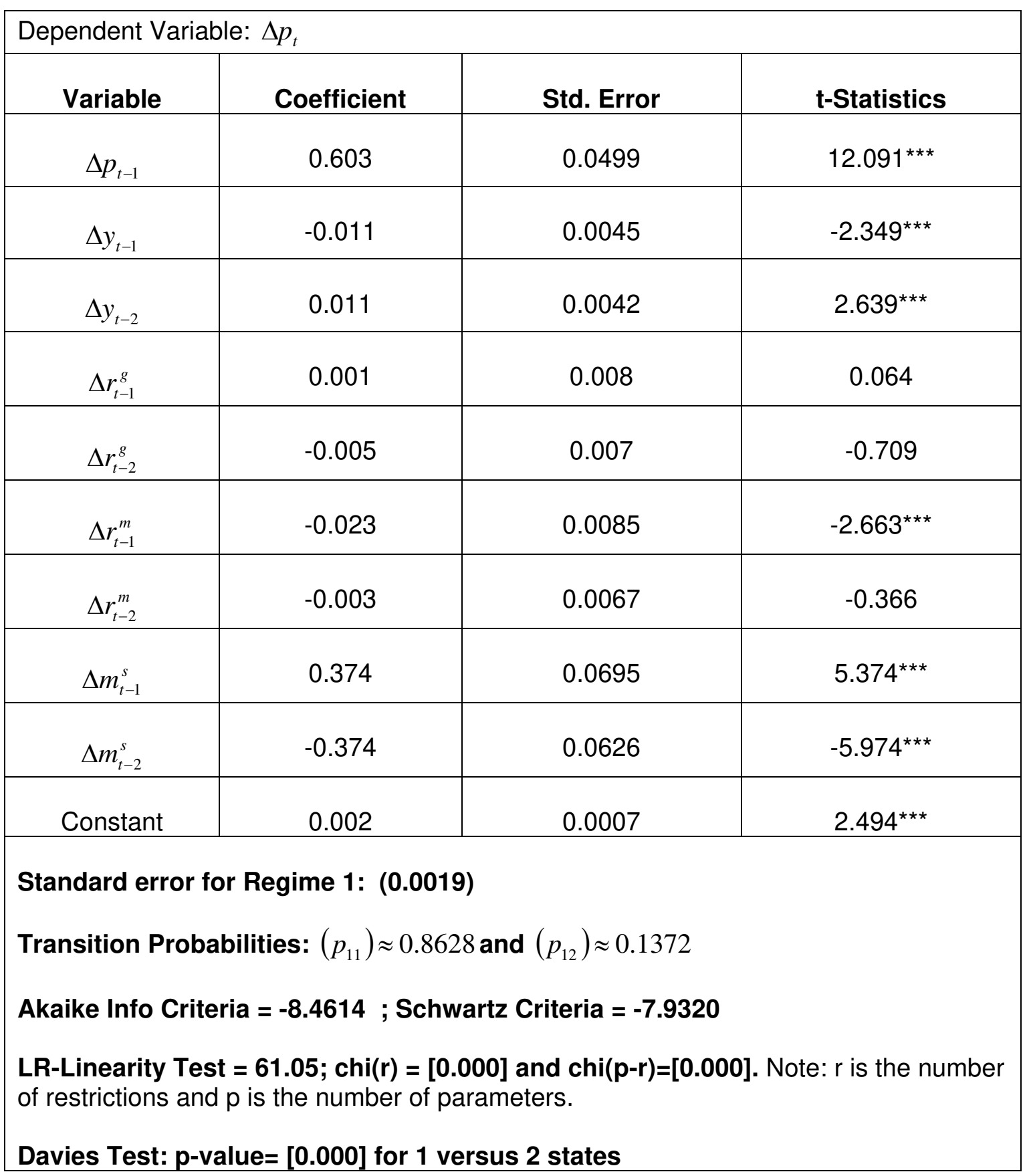

Source: Authors' own calculation.

Note: */10 per cent significant; ${ }^{* *} / 5$ per cent significant; and ${ }^{\star \star *} / 1$ per cent significant 
Table 4: Markov-Switching Test Results for Regime 2

\begin{tabular}{|c|c|c|c|}
\hline \multicolumn{4}{|c|}{ Dependent Variable: $\Delta p_{t}$} \\
\hline Variable & Coefficient & Std. Error & t-Statistics \\
\hline$\Delta p_{t-1}$ & 0.879 & 0.060 & 14.549 \\
\hline$\Delta y_{t-1}$ & -0.011 & 0.005 & $-2.244^{\star \star *}$ \\
\hline$\Delta y_{t-2}$ & -0.004 & 0.005 & -0.931 \\
\hline$\Delta r_{t-1}^{g}$ & -0.016 & 0.014 & -1.178 \\
\hline$\Delta r_{t-2}^{g}$ & 0.027 & 0.014 & $1.930^{*}$ \\
\hline$\Delta r_{t-1}^{m}$ & 0.013 & 0.006 & $2.165^{\star \star \star}$ \\
\hline$\Delta r_{t-2}^{m}$ & -0.015 & 0.006 & $-2.313^{\star * \star}$ \\
\hline$\Delta m_{t-1}^{s}$ & -0.042 & 0.102 & -0.409 \\
\hline$\Delta m_{t-2}^{s}$ & 0.417 & 0.113 & $3.702^{* * \star}$ \\
\hline Constant & -0.004 & 0.001 & $-3.168^{\star \star \star}$ \\
\hline $\begin{array}{l}\text { Standard err } \\
\text { Transition Pr } \\
\text { Akaike Info } \mathrm{C}\end{array}$ & $\begin{array}{l}\text { egime 2: }(0 . \\
\text { ies: }\left(p_{21}\right) \approx 0 \\
=-8.4614 ; \mathbf{S}\end{array}$ & $\begin{array}{l}\left(p_{22}\right) \approx 0.84( \\
\text { riteria }=-7.9\end{array}$ & \\
\hline \multicolumn{4}{|c|}{$\begin{array}{l}\text { LR-Linearity Test }=61.05 ; \text { chi }(r)=[0.000] \text { and } \operatorname{chi}(p-r)=[0.000] \text {. Note: } r \text { is the number } \\
\text { of restrictions and } p \text { is the number of parameters. } \\
\text { Davies Test: } p \text {-value }=[0.000] \text { for } 1 \text { versus } 2 \text { states }\end{array}$} \\
\hline
\end{tabular}

Source: Authors' own calculation.

Note: ${ }^{*} / 10$ per cent significant; ${ }^{* *} / 5$ per cent significant; and ${ }^{* * *} / 1$ per cent significant 
Table 5: MS-VAR Dates for Regime 1 and Regime 2

\begin{tabular}{|c|c|}
\hline \multicolumn{2}{|l|}{ Regime 1: Stable Regime } \\
\hline Period & Number of Months \\
\hline $2001: 3-2001: 10$ & 8 \\
\hline $2002: 4$ - 2003:4 & 13 \\
\hline $2004: 4-2005: 1$ & 10 \\
\hline $2005: 4-2006: 1$ & 10 \\
\hline $2006: 4-2007: 1$ & 10 \\
\hline $2007: 4-2007: 11$ & 8 \\
\hline $2009: 4-2009: 9$ & 6 \\
\hline $2011: 7-2011: 12$ & 6 \\
\hline \multicolumn{2}{|l|}{ Total Number of Months: 71 months } \\
\hline \multicolumn{2}{|l|}{ Regime 2: Volatile Regime } \\
\hline Period & Number of Months \\
\hline $2001: 11-2002: 3$ & 5 \\
\hline $2003: 5-2004: 3$ & 11 \\
\hline $2005: 2-2005: 3$ & 2 \\
\hline $2006: 2-2006: 3$ & 2 \\
\hline $2007: 2-2007: 3$ & 2 \\
\hline $2007: 12-2009: 3$ & 16 \\
\hline $2009: 10-2011: 6$ & 21 \\
\hline
\end{tabular}

Source: Authors' own calculation. 
Table 6: Markov-Switching Test Results for Regime 1

“Domestic-Component of Gold Price"

\begin{tabular}{|c|c|c|c|}
\hline \multicolumn{4}{|c|}{ Dependent Variable: $\Delta p_{t}$} \\
\hline Variable & Coefficient & Std. Error & t-Statistics \\
\hline$\Delta p_{t-1}$ & 0.570 & 0.061 & $9.349^{* * *}$ \\
\hline$\Delta y_{t-1}$ & -0.034 & 0.004 & $-8.141^{\star * *}$ \\
\hline$\Delta y_{t-2}$ & -0.011 & 0.004 & -0.261 \\
\hline$\Delta r_{t-1}^{d g}$ & -0.005 & 0.011 & -0.414 \\
\hline$\Delta r_{t-2}^{d g}$ & 0.019 & 0.012 & 1.607 \\
\hline$\Delta r_{t-1}^{m}$ & 0.011 & 0.009 & 1.298 \\
\hline$\Delta r_{t-2}^{m}$ & -0.024 & -0.006 & $-4.062^{\star \star \star}$ \\
\hline$\Delta m_{t-1}^{s}$ & 0.266 & 0.074 & $3.580^{* \star *}$ \\
\hline$\Delta m_{t-2}^{s}$ & -0.245 & 0.067 & $-3.686^{* * *}$ \\
\hline Constant & 0.002 & 0.001 & $1.820^{*}$ \\
\hline \multicolumn{4}{|c|}{ Standard error for Regime 1: (0.0019) } \\
\hline \multicolumn{4}{|c|}{$\begin{array}{l}\text { LR-Linearity Test }=71.50 ; \operatorname{chi}(r)=[0.000] \text { and } \operatorname{chi}(p-r)=[0.000] \text {. Note: } r \text { is the number } \\
\text { of restrictions and } p \text { is the number of parameters. }\end{array}$} \\
\hline Davies Test: & {$[0.000]$ for } & tates & \\
\hline
\end{tabular}

Source: Authors' own calculation.

Note: ${ }^{*} / 10$ per cent significant; ${ }^{* *} / 5$ per cent significant; and ${ }^{* *} / 1$ per cent significant 
Table 7: Markov-Switching Test Results for Regime 2

"Domestic-Component of Gold Price"

\begin{tabular}{|c|c|c|c|}
\hline \multicolumn{4}{|c|}{ Dependent Variable: $\Delta p_{t}$} \\
\hline Variable & Coefficient & Std. Error & t-Statistics \\
\hline$\Delta p_{t-1}$ & 1.012 & 0.059 & $16.896^{\star \star \star}$ \\
\hline$\Delta y_{t-1}$ & 0.011 & 0.007 & 1.567 \\
\hline$\Delta y_{t-2}$ & 0.011 & 0.007 & 1.512 \\
\hline$\Delta r_{t-1}^{d g}$ & -0.002 & 0.016 & -0.147 \\
\hline$\Delta r_{t-2}^{d g}$ & 0.033 & 0.017 & $1.941^{*}$ \\
\hline$\Delta r_{t-1}^{m}$ & 0.017 & 0.005 & $3.085^{\star * \star}$ \\
\hline$\Delta r_{t-2}^{m}$ & -0.039 & 0.008 & $-5.111^{* \star *}$ \\
\hline$\Delta m_{t-1}^{s}$ & 0.055 & 0.109 & 0.499 \\
\hline$\Delta m_{t-2}^{s}$ & 0.411 & 0.122 & $3.377^{* * *}$ \\
\hline Constant & -0.008 & 0.002 & $-5.049^{* * *}$ \\
\hline \multicolumn{4}{|c|}{ Transition Probabilities: $\left(p_{21}\right) \approx 0.1885$ and $\left(p_{22}\right) \approx 0.8115$} \\
\hline \multicolumn{4}{|c|}{ Akaike Info Criteria = -8.5795 ; Schwartz Criteria = -7.9835 } \\
\hline \multicolumn{4}{|c|}{$\begin{array}{l}\text { LR-Linearity Test }=71.50 ; \operatorname{chi}(r)=[0.000] \text { and } \operatorname{chi}(p-r)=[0.000] \text {. Note: } r \text { is the number } \\
\text { of restrictions and } p \text { is the number of parameters. }\end{array}$} \\
\hline Davies Test: & {$[0.000]$ for } & 2 states & \\
\hline
\end{tabular}

Source: Authors' own calculation.

Note: ${ }^{*} / 10$ per cent significant; ${ }^{* *} / 5$ per cent significant; and ${ }^{* * *} / 1$ per cent significant 


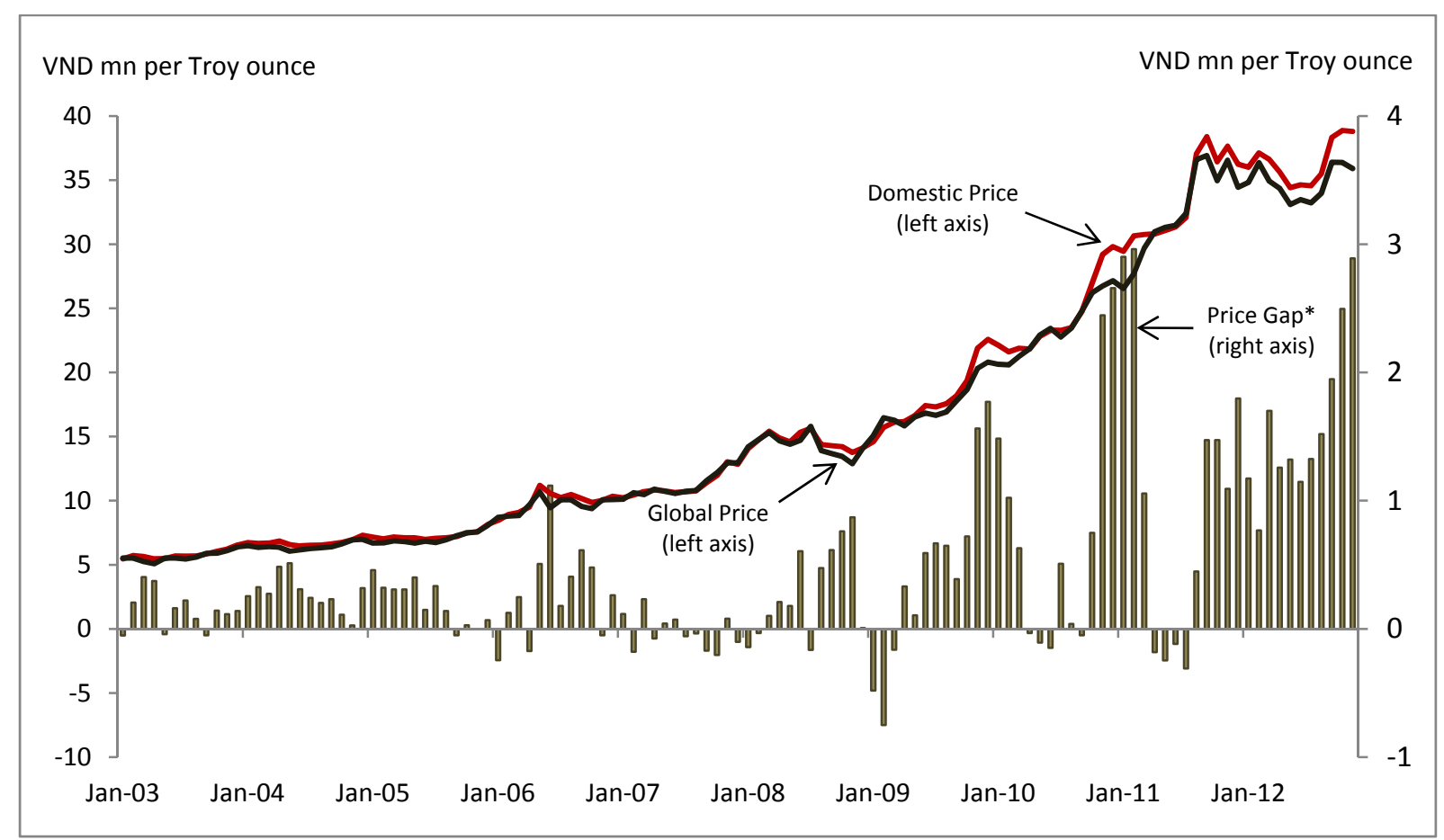

Source: Bloomberg and General Statistics Office of Vietnam

Note: */Price gap is calculated by taking the difference between the domestic gold price in Vietnam and the global gold price on the monthly average basis. Prices and price gap are quoted in millions of Vietnamese dong per Troy ounce.

Figure 2: Headline Inflation and Gold Price: Annual Change

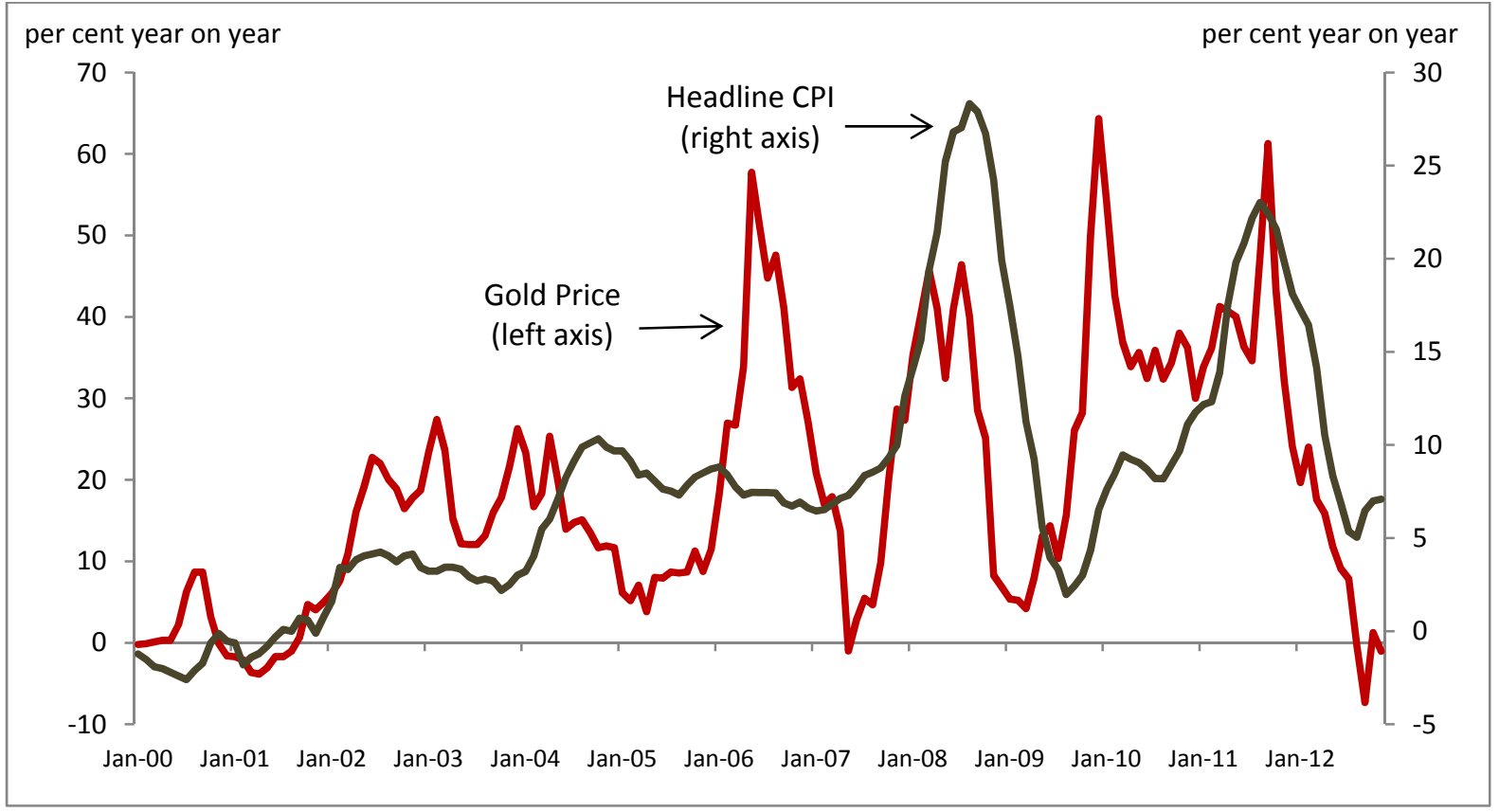

Source: General Statistics Office of Vietnam 
Figure 3: Vietnam External Trade of Valuable Stones and Metals, including Gold

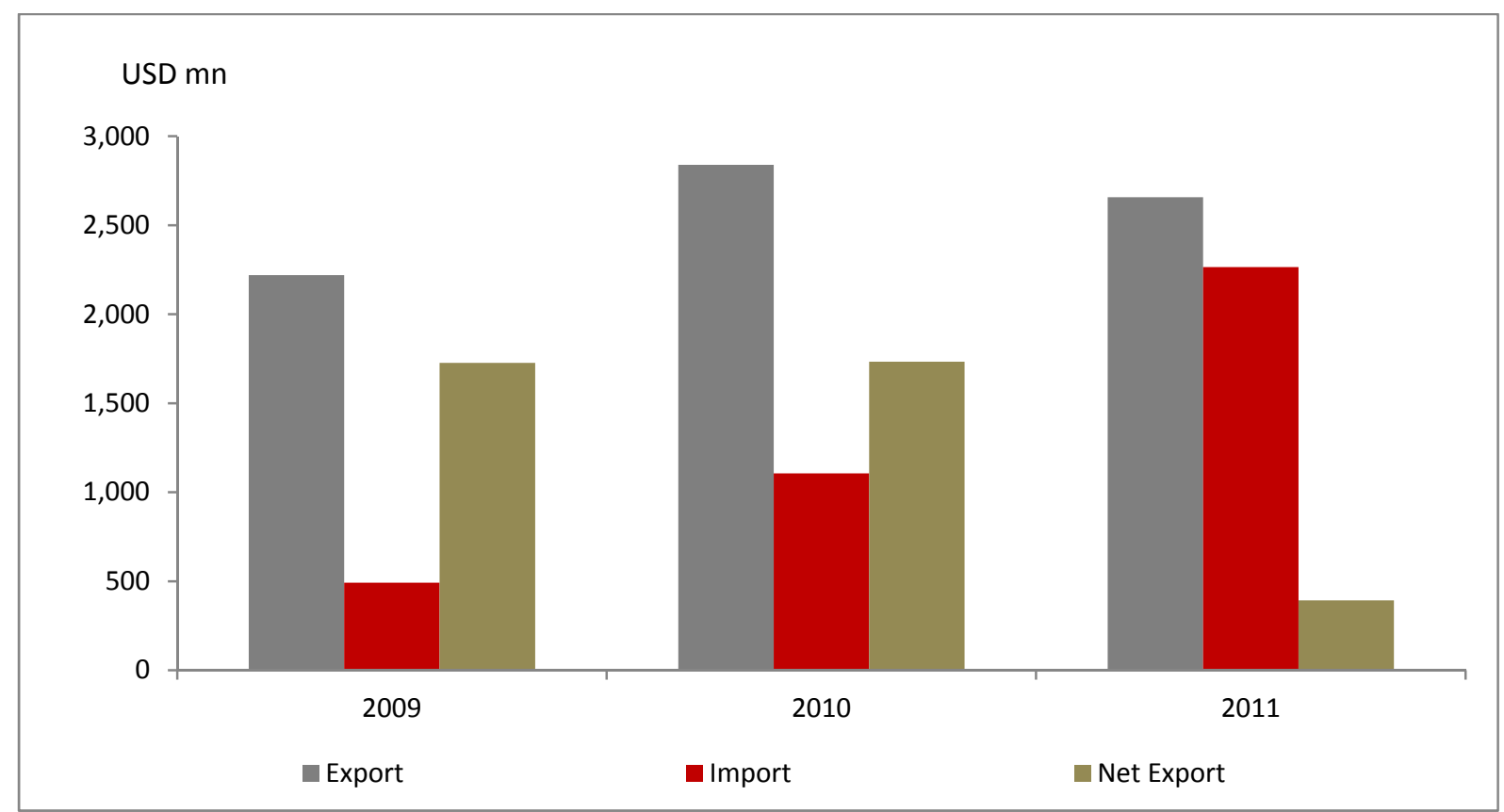

Source: General Statistics Office of Vietnam

Figure 4: Recent Gold Price Developments: May 2012 - March 2013

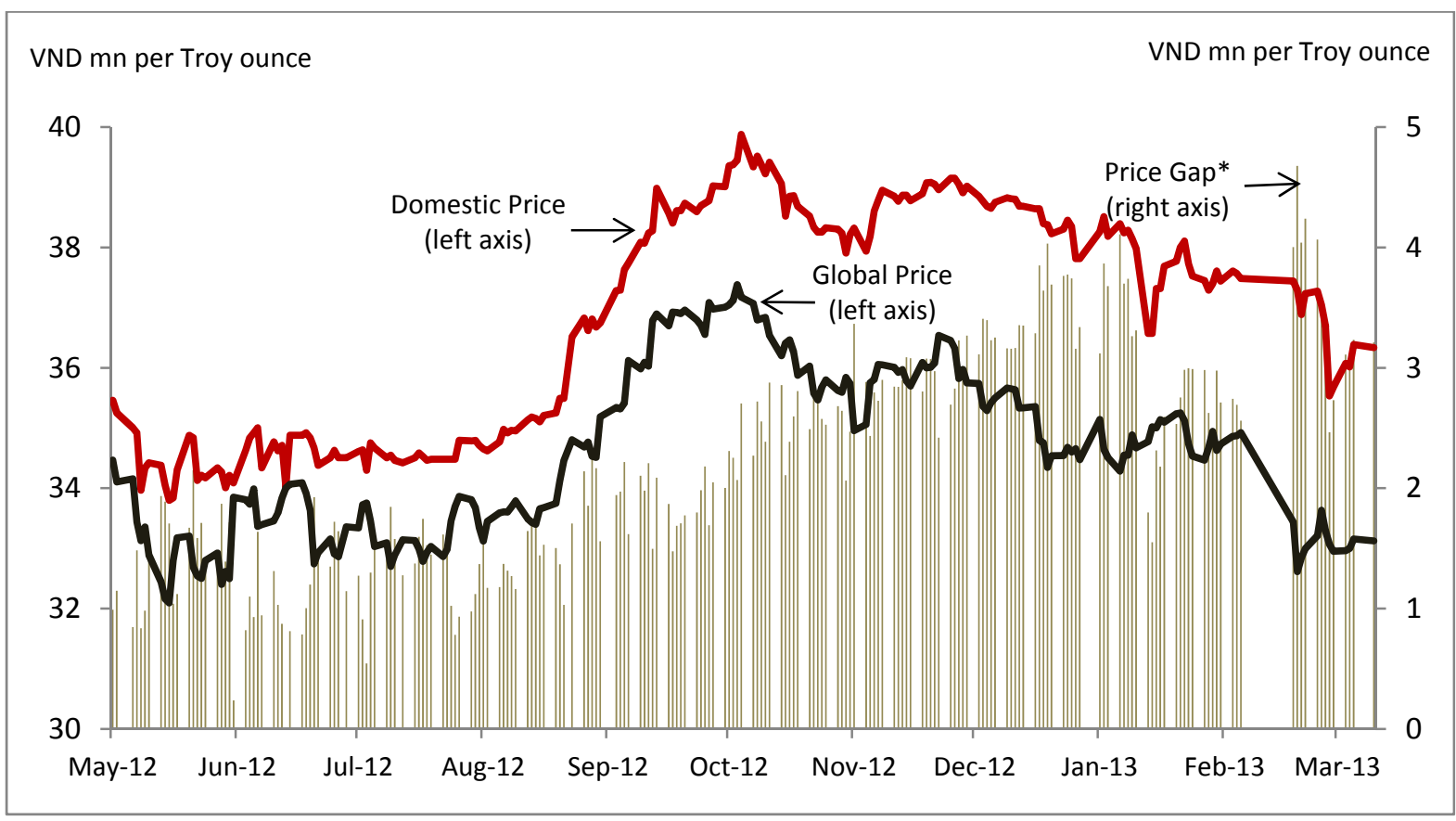

Source: Bloomberg

Note: */Price gap is calculated by taking the difference between the domestic gold price in Vietnam and the global gold price on the daily basis. Prices and price gap are quoted in millions of Vietnamese dong per Troy ounce. 